\title{
High-level soluble expression and enzymatic characterization of Burkholderia sp. lipase with steryl ester hydrolysis activity in E. coli
}

Zhengyu Shu ( $\square$ shuzhengyu@fjnu.edu.cn )

College of Life Sciences, Fujian Normal University (Qishan campus), Fuzhou 350117

https://orcid.org/0000-0002-4528-8306

Feng Li

Fujian Normal University

Wenjing Jia

Fujian Normal University

Xiangduo Mu

Fujian Normal University

Hong Lin

Fujian Normal University

Yanru Liu

Fujian Normal University

Jianzhong Huang

Fujian Normal University

\section{Research article}

Keywords: Burkholderia sp., Lipase, Soluble expression, Enzymatic characterization, Steryl ester hydrolase activity

Posted Date: July 22nd, 2019

DOI: https://doi.org/10.21203/rs.2.11778/v1

License: (c) (i) This work is licensed under a Creative Commons Attribution 4.0 International License.

Read Full License 


\section{Abstract}

Background Burkholderia cepacia lipase is an important industrial biocatalyst for biodiesel production and chiral pharmaceutical synthesis. Heterologous soluble expression of lipase lipA gene from B. cepacia in Escherichia coli highly depends on co-expression of its cognate foldase gene, lipB. However, the interaction between recombinant lipase LipA and chaperonin LipB is rather complicated and confusing. In this research, various systems of lipA/lipB co-expression combinations are investigated to obtain highlevel soluble expression of lipA, respectively. Results The best co-expression combination system for lipA and lipB is E. coli Origami 2 (DE3)/pETDuet-lipB(MCS1)/lipA(MCS2). The soluble expression level of lipA is $100.4 \mathrm{U} / \mathrm{OD} 600$ towards 4-nitrophenyl laurate hydrolysis. The recombinant LipA can be rapidly isolated from cell-free supernatant of recombinant E. coli lysate using HisTrap HP affinity chromatography column, and the lipA/LipB complex is obtained. Enzymatic characterization analysis shows that the purified LipA is a mesothermal and alkaline enzyme. LipA displays preference for medium-chain-length acyl groups (C10-C12) and sn-1,3 regioselectivity. Besides triacylglycerol hydrolase activity (EC. 3.1.1.3), LipA also displays steryl ester hydrolase activity (EC. 3.1.1.13). The specific activity of LipA towards 4nitrophenyl decanoate and cholesterol linoleate are $638.9 \mathrm{U} / \mathrm{mg}$ and $1111.5 \mathrm{mU} / \mathrm{mg}$, respectively. Conclusions Host strain E. coli Origami 2 (DE3), lipB locus at MCS1 on the dual expression cassette plasmid pETDuet, and low-temperature induction contribute to the soluble expression of lipA. Recombinant LipA displays both triacylglycerol hydrolase activity and steryl ester hydrolase activity.

\section{Background}

Lipase (triacylglycerol hydrolase, EC 3.1.1.3) hydrolyzes triacylglycerols into glycerol and fatty acids, or the reverse reaction of esterification. Besides hydrolysis reaction, microbial lipase also catalyzes alcoholysis reaction, ammonolysis reaction, or transesterification reaction in non-aqueous system, in which lipase displays strict enantioselectivity, and regioselectivity [1]. As an important industrial biocatalyst, microbial lipase is used widely in many industrial fields, including biodiesel systnesis, biodegradable polymers production, and pharmaceuticals preparation $[2,3]$.

Among the known microbial lipase resources, Burkholderia cepacia lipase is known as an enantioselective biocatalyst for synthesis reactions because of its' distinctive structural characterization of the funnel-like active site $[4,5,6]$. Moreover, $B$. cepacia lipase also exhibits excellent organic solvent tolerance and is a promising biocatalyst for biodiesel production $[7,8]$. Disulfide bond and calcium ion in the 3D molecular structure contributes to the stability of $B$. cepacia lipase, respectively $[9,10]$. According to the classification standard for lipolytic enzyme family, B. cepacia lipase belongs to I.2 subfamily of true lipases [11,12]. The functional expression and secretion in an active form of 1.2 subfamily lipases highly depends on a chaperone protein (also named as lipase-specific foldase) [13,14].

Because most $B$. cepacia strains are human opportunistic pathogens, it is severely regulated to construct recombinant $B$. cepacia strains using homologous expression system for lipase production in industry [8,15-17]. To obtain high-yield functional recombinant lipase from Burkholderia sp., cell-free protein 
synthesis systems and foldase-assisted refolding of recombinant lipase in vitro are used to produce the functional recombinant lipase at the early stage, respectively $[18,19]$. In recent years, two-plasmid coexpression systems or dual expression cassette plasmid systems are used to co-express lipase gene ( $($ ipA) with its cognate foldase gene ( $\operatorname{lip} B$ ),, and a method which enabled to obtain high yields of functional recombinant lipase LipA is obtained [20-23].

In this research, various systems of $\operatorname{lip} A / \operatorname{lip} B$ co-expression combinations are screened and then the best co-expression combination system, E. coli Origami 2 (DE3)/pETDuet-lipB(MCS1)/lipA(MCS2), is selected for high-yield production of functional LipA. The recombinant LipA is purified and enzymatic characterization is determined. Besides triacylglycerol hydrolase activity (EC. 3.1.1.3), recombinant LipA also displays steryl ester hydrolysis activity (EC. 3.1.1.13).

\section{Results}

Effects of different co-expression combination systems on the soluble expression of lipA

In the dual expression cassette plasmid system, gene loci of $\operatorname{lip} A$ and $\operatorname{lip} B$ on the plasmid were the key factors for the functional soluble expression of lipA. The lipase activity from the supernatant of recombinant $E$. coli lysate reached $6.5 \pm 0.2 \mathrm{U} / \mathrm{OD}_{600}$ when $\operatorname{lip} A$ and $\operatorname{lip} B$ were inserted into MCS2 and MCS1 of pACYCDuet, respectively. In contrast, the lipase activity was only $1.8 \pm 0.1 \mathrm{U} / \mathrm{OD}_{600}$ when lipA and lipB were inserted into MCS1 and MCS2 of pACYCDuet, respectively (Table 1, E. coli BL21 (DE3) as the expression host). A similar experimental result was also observed when pETDuet was selected as the dual expression cassette plasmid. The lipase activity increased from $1.7 \pm 0.1 \mathrm{U} / \mathrm{OD}_{600}$ to $3.9 \pm 0.1 \mathrm{U} / \mathrm{OD}_{600}$ by gene locus interchange between lipA and lipB (Table 1, E. coli BL21 (DE3) as the expression host). Aamand et al. (1994) also reported that the presynthesized LipB could activate the recombinant LipA [24].

In the two-plasmid co-expression systems, types of plasmid carrying lipA and lipB showed the important effect on the functional soluble expression of $\operatorname{lip} A$. When lipA and lipB was inserted into MCS of pET28a and MCS1 of pACYCDuet, respectively, no lipase activity was detected from the supernatant of recombinant $E$. coli lysate (Table 1, E. coli BL21 (DE3) as the expression host). In contrast, a low lipase activity, 2.6 $\pm 0.1 \mathrm{U} / \mathrm{OD}_{600}$, was obtained when lipA and lipB were inserted into MCS1 of pACYCDuet and MCS of pET28a, respectively. Ihara et al. (1995) reported that it was the recombinant LipA, rather than the recombinant LipB, that was prone to form inclusion body under the control of T7 promoter [25]. Low-level expression of lipA using low-copy number plasmid (pACYCDuet or pETDuet used in this study) contributed to form functional soluble LipA. Among the investigated two-plasmid co-expression systems, plasmid combinations of pACYCDuet with pETDuet showed excellent effect on the functional soluble expression of lipA, in which lipase activity was as high as from $9.9 \pm 0.4 \mathrm{U} / \mathrm{OD}_{600}$ to $12.6 \pm 1.0 \mathrm{U} / \mathrm{OD}_{600}$ (Table 1, E. coliBL21 (DE3) as the expression host).

In previous report, co-expression of an additional copy of chaperone lip $B$ gene resulted in a considerable increase of functional LipA yield in native host strain $[14,26]$. However, no statistical significance of 
functional LipA yield was observed in E. coli expression system when an additional copy of lipB was introduced into the co-expression combination system of lipA and lipB. Lipase activity was $6.5 \pm 0.2$ $\mathrm{U} / \mathrm{OD}_{600}$ in the dual expression cassette plasmid system of pACYCDuet-B1A2. However, lipase activity still was $6.3 \pm 0.1 \mathrm{U} / \mathrm{OD}_{600}$ in the two-plasmid co-expression system of pACYCDuet-B1A2 and pETDuet-B1, in which an additional copy of lipB was introduced using plasmid pETDuet-B1 (Table 1, E. coli BL21 (DE3) as the expression host).

E. coli expression strain was another key element for the functional soluble expression of lipA from Burkholderia sp.. In the 3D structural model of LipA from B. cepacia, a disulfide bond existed between Cys ${ }^{190}$ and Cys $^{270}$ [10]. Refolding in vitro of LipA from B. cepacia indicated that the functional LipA was highly depended on the correct formation of a disulfide bond between Cys ${ }^{190}$ and Cys ${ }^{270}$ [27]. The functional soluble expression yield of lipA from Burkholderia sp. was improved by fusing LipA with the Nterminal peptide tags of Dsb-family chaperones [28]. Compared with that in E. coli BL21 (DE3), soluble expression yield of lipA in E. coli Origami 2 (DE3) was increased by 1.3-fold to 7.9-fold (Table 1).

\section{Effects of culture temperature on the functional soluble yield of lipA}

From Table 1, a significantly positive effect of low temperature on functional soluble LipA yield was observed. The soluble LipA yield reached $100.4 \pm 0.7 \mathrm{U} / \mathrm{OD}_{600}$ when $E$. coli Origami 2 (DE3)/pETDuet-B1A2 was cultured at $20^{\circ} \mathrm{C}$. While E. coli Origami 2 (DE3)/pETDuet-B1A2 was cultured at $30^{\circ} \mathrm{C}$, soluble LipA yield decreased to $30.9 \pm 0.3 \mathrm{U} / \mathrm{OD}_{600}$ (Table 3, E. coli Origami 2 (DE3) as the expression host). Same results were obtained when other co-expression combinational systems were induced at $20^{\circ} \mathrm{C}$ and $30{ }^{\circ} \mathrm{C}$, respectively. Low temperature culture contributed to not only the correct folding of recombinant protein, but also improving stability, which resulted in productivity enhancement of soluble recombinant protein $[29,30]$.

During exponential phase, growth rates of recombinant $E$. coli BL21(DE3) strains were higher than that of recombinant E. coli Origami 2 (DE3) strains at $20^{\circ} \mathrm{C}$ (Fig. 1A). It were 15 hours for recombinant E. coli BL21(DE3) strains that were taken to reach stationary phases at $20^{\circ} \mathrm{C}$. While for recombinant $E$. coli Origami 2 (DE3) strains, 25 hours were needed to reach stationary phases at $20^{\circ} \mathrm{C}$ (Fig. $1 \mathrm{~A}$ ). No significant difference of cell density existed between recombinant E. coli BL21(DE3) strains and recombinant $E$. coli Origami 2 (DE3) strains during stationary phases (Fig. 1A). However, significant differences of soluble LipA yield existed between recombinant $E$. coli Origami 2 (DE3) strains and recombinant $E$. coli BL21(DE3) strains during stationary phases (Fig. 1B). The highest soluble expression level of lipA from E. coli Origami 2 (DE3)/pETDuet-B1A2 reached $100.4 \mathrm{U} / \mathrm{OD}_{600}$ towards 4-nitrophenyl laurate hydrolysis. The functional soluble yields of lipA reached $132 \mathrm{mg} / \mathrm{L}$ or $73000 \mathrm{U} / \mathrm{L}$.

\section{Purification of recombinant LipA}


There were a 34-kDa band and a 32-kDa band from the purified LipA preparation shown on the SDS-PAGE gel (lane 2, Fig. 2). In the dual expression cassette plasmid system of E. coli Origami 2 (DE3)/pETDuet$B 1 A 2$, lipA was inserted into the MCS2, while lipB were inserted into the MCS1 of pETDuet. Consequently, S-tag and His-tag should be fused to the C-terminus of LipA and N-terminus of LipB, respectively. It was confirmed using western blotting analysis of anti-His tag antibody that the $32-\mathrm{kDa}$ band originated from LipB (lane 1, Fig. 2). Given the characteristic of HisTrap HP affinity chromatography column and interaction between LipA and LipB, it was LipB that was firstly combined with His-tag of matrix materials and LipA was then combined with LipB. Recombinant LipA showed the same relative molecular weight, $34 \mathrm{kDa}$ (lane 2, Fig. 2), as the native extracellular lipase from Burkholderia sp. ZYB002 [31]. In other reports on co-expression of lipA/lipB from B. cepacia or P. aeruginosa in E. coli, the purified preparation also simultaneously contained the recombinant LipA and LipB [20,21]. Pauwels and Van Gelder (2008) even developed a rapid affinity-based purification method of a bacterial lipase through steric chaperone interactions [32].

Using one-step purification procedure of HisTrap HP affinity chromatography column, recombinant LipA was purified with a recovery of $68.6 \%$ and a fold purification of 2.6 . The specific activity of recombinant LipA towards 4-nitrophenyl laurate hydrolysis was $547.0 \mathrm{U} / \mathrm{mg}$. Because recombinant LipA exists in the form of LipA/LipB complex, the actual value of specific activity of LipA is approximate two times as much as the tested value, and is same as that of the native extracellular lipase from Burkholderia sp. ZYB002 [31].

\section{Enzymatic characterization of LipA}

As shown in Fig. 3A and Fig. 3B, the recombinant LipA was a mesothermal and alkaline enzyme. The optimum temperature and $\mathrm{pH}$ of LipA was $40^{\circ} \mathrm{C}$ and 8.0, respectively. The half-time of the recombinant LipA was about 36 min at $40^{\circ} \mathrm{C}$ (Fig. 3C). The stability of LipA was lower in acidic buffer solution than in alkaline buffer solution (Fig. 3D). However, the residual activity of LipA was only $70 \%$ of the initial activity after incubation in $20 \mathrm{mmol} / \mathrm{L} \mathrm{pH} 8.0 \mathrm{Na}_{2} \mathrm{HPO}_{4}-\mathrm{NaH}_{2} \mathrm{PO}_{4}$ buffer for $4 \mathrm{~h}$ at $4{ }^{\circ} \mathrm{C}$ (Fig. 3D). Among the investigated bivalent metal ions and EDTA, only $\mathrm{Mg}^{2+}$ was found to enhance LipA activity, whereas, $\mathrm{Fe}^{2+}$, $\mathrm{Zn}^{2+}$ and $\mathrm{Cu}^{2+}$ ions strongly inhibited LipA activity (Fig. 4).

Partial hydrolysis of triolein by the recombinant LipA resulted in three kinds of hydrolysis products, including 1,2-diolein, oleic acid, 1-monoolein (Fig. 5), which showed that LipA cleaved only the 1,3positioned ester bonds and displayed $s n-1,3$ regioselectivity. Trace amounts of 1-monoolein in the hydrolyzed products might be related to acyl migration of $s n-2$ to $s n-1$, which occurs spontaneously in glycerides [33].

The recombinant LipA showed a preference for medium chain length fatty acid esters (C10-C12) when assayed using 4-nitrophenyl derivatives (Table 2). Recombinant LipA exhibited a simple MichaelisMenten kinetics for 4-nitrophenyl decanoate hydrolysis. The values of $K_{\mathrm{m}}$ and $V_{\max }$ of LipA were 0.57 
$\mathrm{mmol} \cdot \mathrm{L}^{-1}$ and $22964 \mu \mathrm{mol} \cdot \mathrm{min}^{-1} \cdot \mathrm{mg}^{-1}$, respectively. Among the determined four steryl esters, LipA showed the highest hydrolysis activity towards cholesterol linoleate, and specific activity reached 1111.5 $\mathrm{mU} / \mathrm{mg}$ (Table 2). Kontkanen et al. (2004) also reported that some commercial lipase preparations displayed steryl esterase activity. However, the steryl esterase activity from lipase preparations was considerably lower than the native lipase activity [34].

\section{Discussion}

In native Burkholderia cepacia strain, lipA and lipB usually form an operon suggesting a 1 to 1 ratio for both lipA and lipB expression $[35,36]$. However, LipB acted as multi-turnover catalysts to direct lipase folding, and expression yield of $\operatorname{lip} B$ was lower than lipA in native host strains [14,37]. While LipA and LipB formed a stable complex, in which LipB acted as single-turnover catalysts to direct lipase folding in heterologous host, E. coli strains21,38]. Both El Khattabi et al. (2000) and Quyen et al. (1999) reported that an excess of LipB was the prerequisite for correct LipA folding in E. coli host [19,38]. Moreover, highlevel active LipA could be obtained only when LipB was synthesized first in two-plasmid co-expression systems in E. coli host [24]. The similar result was also observed in this research. High level soluble LipA was obtained only when lipB and lipA was inserted into the MCS1 site and MCS2 site on the dual expression cassette plasmid pETduet, respectively. Compared with that from pETDuet-A1B2, soluble expression yield of LipA from pETDuet-B1A2 was increased by 28.7 fold (Table 1, E. coli Origami 2 (DE3) as the expression host).

DsbA-DsbB disulfide bond formation system existed in native B. cepacia strains [39]. Disulfide bond in Burkholderia sp. lipase played a key role in activating lipolytic activity and stabilizing the 3D structure $[9,40]$. In heterologous strain, the soluble expression yield of Burkholderia sp. lipase was improved by coexpression of cytoplasmic chaperone GroEL/ES, which could facilitate refolding of disulfide-bond [28,41]. Host strain was another substitution strategy for high-level soluble expression of lipase with disulfidebond in 3D structure. To produce recombinant Rhizopus oryzae lipase in E. coli, the insoluble and inactive protein pellet was obtained when E. coli BL21(DE3) or E. coli Rosetta was selected as the expression host strain. While recombinant Rhizopus oryzae lipase was expressed as soluble and active forms when E. coli Origami (DE3) strain was used as the expression host strain [42]. In this research, soluble expression level of LipA from E. coli Origami 2 (DE3)/pETDuet-B1A2 was $100.4 \mathrm{U} / \mathrm{OD}_{600}$, while from E. coli BL21(DE3)/pETDuet-B1A2, soluble expression level of LipA was only $49.7 \mathrm{U} / \mathrm{OD}_{600}$.

When E. coli was selected as host strain for co-expression of lipA and lipB from Burkholderia sp., LipA/LipB complex would be formed and it was difficult to isolate LipA from LipA/LipB complex [43]. In previous research work, a low-Mr compound was purified from cell-free lysate of Pseudomonas sp. and then identified as Glutathione, which could facilitate the dissociation of LipA/LipB complex and liberate free active lipase [44,45]. In this work, E. coli Origami 2 (DE3) was selected as the expression host, which would enhance disulfide bond formation. However, recombinant LipA was still aggregated with recombinant LipB. To facilitate the dissociation of LipA/LipB complex, $1 \%(v / V)$ Triton X-100, 1mol/L Urea, $1 \mathrm{~mol} / \mathrm{L}$ ammonium sulfate, or $2 \mathrm{mmol} / \mathrm{L} \mathrm{CaCl}_{2}$ was added into the elution buffer solution for 
HisTrap HP affinity chromatography column, respectively. However, the recombinant LipA was not still dissociated from LipA/LipB complex (data not shown). Moreover, Kim et al. (2001) reported that lipaseProline ${ }^{112}$ Glutamine mutant could correctly fold and display lipase activity in the absence of chaperone LipB. It is necessary to further investigate the molecular mechanism on folding of LipA and dissociation of LipA/LipB complex [46].

Microbial steryl esterase (EC. 3.1.1.13) have tremendous application potential in steroids synthesis [47]. Nevertheless, sources of microbial steryl esterases were extremely limited and most of the reported microbial steryl esterases should, in fact, be classified as microbial lipases (EC. 3.1.1.3)[48]. Steryl esterase from B. cepacia ST200 was firstly reported by Takeda et al. (2006) and enzymatic characterization for steryl esterase activity was determined. However, lipase activity of this enzyme was not tested [49]. The amino acid sequence identity was over $93 \%$ between steryl esterase from $B$. cepacia ST200 and LipA from Burkholderia sp. ZYB002 [49,50]. In this research, both lipase activity and steryl esterase activity were determined from LipA from Burkholderia sp. ZYB002 (Table 2). Moreover, microbial lipase could act on some non-triglyceride substrates and displayed promiscuous activity $[51,52]$. In previous reports, a few microbial lipases could catalyze hydrolysis reaction of steryl esters [34]. Because of the structural difference between triglyceride and steryl ester, hydrolysis efficiency of steryl ester catalyzed by lipase was always low, and it was necessary to improve catalysis activity towards steryl esters using protein engineering technology.

\section{Conclusions}

Host strain, gene loci of $\operatorname{lip} A$ and $\operatorname{lip} B$ on the dual expression cassette plasmid pETDuet, and lowtemperature induction $\left(20^{\circ} \mathrm{C}\right)$ impacted positive effect on the soluble expression level of lipA. The best expression system was E. coli Origami 2 (DE3)/pETDuet-B1A2, in which lipA was inserted into MCS2 and $\operatorname{lip} B$ was inserted into MCS1. Under the above conditions, the highest soluble expression level of lipA reached $100.4 \mathrm{U} / \mathrm{OD}_{600}$ towards 4-nitrophenyl laurate hydrolysis. The functional soluble yields of LipA reached $132 \mathrm{mg} / \mathrm{L}$ or $73000 \mathrm{U} / \mathrm{L}$. Besides triacylglycerol hydrolase activity, recombinant LipA also displayed steryl ester hydrolase activity.

\section{Methods}

\section{Strains, plasmids and reagents}

Bacterial strains and plasmids used in this study were listed in Table 3. Briefly, E. coli DH5a was used as the host strain for plasmid amplification, while E. coliBL21 (DE3) or E. coli Origami 2 (DE3) were used to express lipase gene (lipA) and the cognate foldase gene (lipB),, respectively.

Restriction endonucleases, high-fidelity DNA polymerases, PCR product purification kit, $\mathrm{T}_{4}$-DNA ligase, DNA gel extraction kit, DNA marker and protein marker were purchased from TaKaRa Biotechnology Co. Ltd. (Dalian, China). DNA sequencing and oligonucleotide primers synthesis was performed by Sangon 
Biotechnology Co. Ltd. (Shanghai, China). Various $p$-nitrophenyl fatty acid esters, cholesterol esters, triolein, oleic acid, 1,3-diolein, 1,2-diolein and 1-monoolein were purchased from Sigma-Aldrich (China). Silica gel GF254 was purchased from Haiyang Chemical Co. Ltd. (Qingdao, China). HisTrap HP affinity chromatography column $(1 \mathrm{~mL})$ was purchased from GE Healthcare Life Sciences (China). All other Chemical reagents were of analytical grade unless otherwise stated and purchased from Sinopharm Chemical reagent Co. Ltd. (China).

\section{Construction of recombinant plasmids}

To discriminate lipase and its cognate lipase-specific foldase, lipase and foldase from Burkholderia sp. ZYB002 were named as LipA and LipB, respectively. The corresponding gene symbols of LipA and LipB were designated as lipA and IipB, respectively. Recombinant plasmids used in this research were listed in Table 3. Insertion sites of $\operatorname{lip} A$ and (or) lip $B$ were shown on the restriction maps of the recombinant plasmids, respectively (Fig. S1). Construction of recombinant plasmids was as follows:

Recombinant plasmids pETDuet-A1B2, pACYCDuet-A1, and pETDuet-B2 were derived from pEDSF-lipBlipA, respectively [50]. Plasmid pEDSF-lipB-lipA was firstly double digested by the restriction endonucleases, $B a m \mathrm{H} \otimes$ and Hind $\nabla$, followed by $B g / \nabla$ and $X h o \nabla$ digestion. The recovered DNA fragments of IipA and (or) lipB were ligated into the corresponding endonuclease-digested plasmid, pETDuet, pACYCDuet, and pETDuet, respectively.

Except for the above mentioned recombinant expression plasmids, other recombinant expression plasmids listed in Table 3 were constructed as follows. The DNA fragments of $\operatorname{lip} A$ and $\operatorname{lip} B$ were amplified by PCR using plasmid pMD18T-lipAB as the template [50]. The oligonucleotide sequences of PCR primers, PCR primer pairs, annealing temperatures, and PCR products were listed in Table 4 . The resulting PCR products were digested with the restriction endonucleases (shown in the oligonucleotide sequences of PCR primer in Table 4) and then ligated into the corresponding endonuclease-digested expression vector pACYCDuet, pETDuet, and pET28a, respectively.

All of the resulting recombinant plasmids were transformed into $E$. coli $\mathrm{DH} 5 \mathrm{a}$, and the reading frames were confirmed by DNA sequencing.

\section{Co-expression of lipA with lipB in E. coli}

To obtain high-yield soluble expression of lipA, various systems of lipA/lipB co-expression combinations were screened, including two-plasmid co-expression systems and dual expression cassette plasmid systems. Total eleven co-expression combination systems of lipA with lipB were investigated (Table 1).

Effect of culture temperature and types of expression host strain on the soluble expression yield of lipA were further investigated. $30^{\circ} \mathrm{C}$ and $20^{\circ} \mathrm{C}$ were set for the culture temperature, respectively. 
Simultaneously, E. coli BL21 (DE3) and E. coli Origami 2 (DE3) were selected as the expression host strain, respectively.

$50 \mathrm{~mL}$ of Luria-Bertani medium supplemented with antibiotic in 250-mL conical flask was used to produce the soluble LipA on orbital shaking incubator at $220 \mathrm{rpm}$. The final concentration of Chloramphenicol, Kanamycin, and Ampicillin was $150 \mu \mathrm{g} / \mathrm{mL}, 50 \mu \mathrm{g} / \mathrm{mL}$, and $60 \mu \mathrm{g} / \mathrm{mL}$, respectively. When the cell density $\left(\mathrm{OD}_{600 \mathrm{~nm}}\right)$ reached 0.6 , IPTG was added to the culture medium to the final concentration of $0.5 \mathrm{mmol} / \mathrm{L}$. After $24 \mathrm{~h}$ induction culture, the cell density $\left(\mathrm{OD}_{600 \mathrm{~nm}}\right)$ of every recombinant strains were determined, and then the cell pellets were collected by centrifugation and resuspended in $50 \mathrm{~mL} 20 \mathrm{mmol} / \mathrm{L} \mathrm{Na}{ }_{2} \mathrm{HPO}_{4}-\mathrm{NaH}_{2} \mathrm{PO}_{4}$ buffer (pH7.4). E. colicells were lysed using sonication and then the supernatant was collected for lipase activity assay, respectively. The soluble expression level of LipA was evaluated using total lipase activity per $\mathrm{OD}_{600}$ of the recombinant cell.

\section{Purification of recombinant LipA}

E. coli Origami 2 (DE3)/pETDuet-B1A2 displayed the highest-yield of soluble LipA among the total eleven co-expression combination systems of $\operatorname{lip} A$ with $\operatorname{lip} B$, and was selected for the following large-scale production of functional soluble LipA.

After induction culture, recombinant $E$. coli was collected and then re-suspend in loading buffer

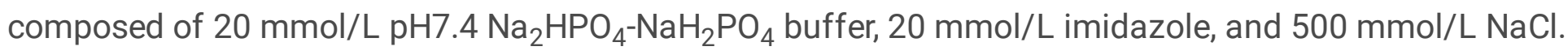
E. coli cells were lysed using sonication and then the supernatant was loaded on a HisTrap HP affinity chromatography column ( $1 \mathrm{~mL}$, GE Healthcare) pre-equilibrated with loading buffer. After the column was rinsed with $10 \mathrm{~mL}$ of loading buffer, recombinant LipA was eluted with $20 \mathrm{~mL}$ of $20-500 \mathrm{mmol} / \mathrm{L}$ imidazole step gradients in the same buffer with a flow rate of $0.3 \mathrm{~mL} / \mathrm{min}$. The purity of the active fractions was monitored by SDS-PAGE on a $10 \%$ separating gel [53]. The fractions with pure LipA was pooled and dialyzed against $20 \mathrm{mmol} / \mathrm{L} \mathrm{Na}_{2} \mathrm{HPO}_{4}-\mathrm{NaH}_{2} \mathrm{PO}_{4}(\mathrm{pH} 7.4)$ buffer overnight at $4^{\circ} \mathrm{C}$. The protein concentration was analyzed using the method of Bradford, with bovine serum albumin as the standard [54].

\section{Lipase activity determination of recombinant LipA}

Lipase activity was determined using spectrophotometric assay method [55] with slight modifications. The reaction mixture consisted of $0.4 \mathrm{mmol} / \mathrm{L}$ of each $p$-nitrophenol ester in $20 \mathrm{mmol} / \mathrm{L} \mathrm{Na}_{2} \mathrm{HPO}_{4^{-}}$ $\mathrm{NaH}_{2} \mathrm{PO}_{4}(\mathrm{pH} 8.0)$ buffer and $30 \mu \mathrm{L}$ the appropriately diluted lipase solution. The kinetics was detected for $5 \mathrm{~min}$ at $410 \mathrm{~nm}$. Under the above condition used, the molar extinction coefficient $\left(\varepsilon_{410}\right)$ of $p$-nitrophenol was $1.15 \times 10^{-2} \mathrm{~L} / \mu \mathrm{mol} . \mathrm{cm}$. 
All reactions were carried out at $40{ }^{\circ} \mathrm{C}$ and $20 \mathrm{mmol} / \mathrm{L} \mathrm{Na}_{2} \mathrm{HPO}_{4}-\mathrm{NaH}_{2} \mathrm{PO}_{4}(\mathrm{pH} 8.0)$ buffer. One unit of lipase activity was defined as the amount of lipase that liberated $1 \mu \mathrm{mol}$ of $p$-nitrophenol from $p$ nitrophenol esters per min. All measurements were carried out three times and the average value was taken.

\section{Cholesterol ester hydrolase activity assay of LipA}

Cholesterol ester hydrolase activity of LipA was assayed using spectrophotometric method as described by Stępień and Gonchar (2013) [56], and the instruction manual for Pseudomomas sp. cholesterol esterase from TOYOBO (USA) with slight modifications. The reaction mixture was composed of 20 $\mathrm{mmol} / \mathrm{L} \mathrm{Na}{ }_{2} \mathrm{HPO}_{4}-\mathrm{NaH}_{2} \mathrm{PO}_{4}$ (pH8.0) buffer, $1.5 \mathrm{mmol} / \mathrm{L}$ 4-aminoantipyrine, $22 \mathrm{mmol} / \mathrm{L}$ 3,5-dichlorodihydroxy benzenesulfonic acid, $10 \mathrm{U} / \mathrm{mL}$ cholesterol oxidase, $5 \mathrm{U} / \mathrm{mL}$ horseradish peroxidase and maximum concentration of dissolved cholesterol esters. The final concentration of cholesterol oleate, cholesterol linoleate, cholesterol palmitate and cholesterol stearate in reaction mixture were $0.07 \mathrm{mmol} / \mathrm{L}$, $0.2 \mathrm{mmol} / \mathrm{L}, 0.12 \mathrm{mmol} / \mathrm{L}$, and $0.1 \mathrm{mmol} / \mathrm{L}$, respectively. The kinetics was detected for $45 \mathrm{~min}$ at $516 \mathrm{~nm}$.

Under the above condition used, the molar extinction coefficient $\left(\varepsilon_{516}\right)$ of $p$-nitrophenol was $2.08 \times 10^{-2} \mathrm{~L} /$ $\mu \mathrm{mol} . \mathrm{cm}$.

All reactions were carried out at $40^{\circ} \mathrm{C}$. One unit of cholesterol ester hydrolase activity was defined as the amount of LipA that liberated $1 \mu \mathrm{mol}$ of cholesterol from cholesterol ester per min. All measurements were carried out three times and the average value was taken.

\section{Effect of pH on activity and stability}

The optimal $\mathrm{pH}$ for lipase activity was determined by incubating lipase substrates in a suitable buffer at various $\mathrm{pH}$ ranging from 6.5 to 9.0 , and the maximum lipase activity was considered $100 \%$. To determine the effect of $\mathrm{pH}$ on lipase stability at $\mathrm{pH}$ ranging from 6.5 to 10.0, aliquots of the concentrated lipase preparation were diluted five-fold in the corresponding buffer and then incubated for $4 \mathrm{~h}$ at $4{ }^{\circ} \mathrm{C}$. The residual lipase activity after incubation was determined and lipase activity at the start was taken as $100 \%$. The corresponding buffers were $\mathrm{Na}_{2} \mathrm{HPO}_{4}-\mathrm{NaH}_{2} \mathrm{PO}_{4}$ (pH6.5-7.5), Tris- $\mathrm{HCl}$ (pH8.0-8.5), and Gly$\mathrm{NaOH}(\mathrm{pH} 9.0-10.0)$, respectively. The final concentrations of various buffers were $20 \mathrm{mmol} / \mathrm{L}$.

\section{Effect of temperature on lipase activity and stability}

The optimal temperature for lipase activity was determined by incubating the standard reaction mixture at different temperatures ranging from $25^{\circ} \mathrm{C}$ to $55^{\circ} \mathrm{C}$, and the maximum lipase activity was considered $100 \%$. To determine the effect of temperature on lipase stability, the lipase preparation was incubated at $40^{\circ} \mathrm{C}$ and aliquots were continuously taken at 5-min interval to assay the residual activity. The lipase activity at the start was taken as $100 \%$. Half-life of thermal inactivation was calculated using the method as described by Zhao and Arnold [57]. 


\section{Effect of metal ions and EDTA on lipase activity}

The purified LipA was dialyzed against $20 \mathrm{mmol} / \mathrm{L} \mathrm{Na}{ }_{2} \mathrm{HPO}_{4}-\mathrm{NaH}_{2} \mathrm{PO}_{4}$ buffer ( $\mathrm{pH} 7.4$ ) overnight at $4^{\circ} \mathrm{C}$, and then the various metal ions and EDTA were added into the dialyzed LipA solution to a final concentration of $1 \mathrm{mmol} / \mathrm{L}$. After incubation at $4^{\circ} \mathrm{C}$ for $1 \mathrm{~h}$, the lipase activity was determined. The lipase activity of the dialyzed LipA solution at the start was considered $100 \%$.

\section{Positional specificity assay}

Positional specificity was determined by analyzing lipolysis products of triolein using thin-layer chromatography (TLC) on silica gel GF254. The experimental procedure was carried out as described by Shu et al. (2016) with slight modifications [50]. In brief, the reaction mixtures consisted of $0.1 \mathrm{mmol} / \mathrm{L}$ of triolein, $1955 \mu \mathrm{L} \mathrm{Na}{ }_{2} \mathrm{HPO}_{4}-\mathrm{NaH}_{2} \mathrm{PO}_{4}(20 \mathrm{mmol} / \mathrm{L}$, pH8.0), and $2 \mathrm{U}(25 \mu \mathrm{L})$ LipA solution. After incubation at $40^{\circ} \mathrm{C}$ for $20 \mathrm{~min}$, the reaction products were extracted with $n$-Hexane and then analyzed by TLC.

\section{Determination of Michaelis-Menten constants}

Enzyme assays with $30 \mu \mathrm{L}$ of purified LipA were performed in $20 \mathrm{mmol} / \mathrm{L} \mathrm{Na} \mathrm{HPO}_{4}-\mathrm{NaH}_{2} \mathrm{PO}_{4}$, pH8.0 at $40^{\circ} \mathrm{C}$ with increasing concentration of 4-Nitrophenyl decanoate from 0.06 to $2.0 \mathrm{mmol} / \mathrm{L}$. LineweaverBurk plots were used to determine the Michaelis-Menten kinetic parameters, $V_{\max }$ and $K_{\mathrm{m}}$, assuming that simple Michaelis-Menten kinetics was followed.

\section{Statistical analysis}

All experiments were carried out three times independently. Data are presented as the average \pm standard deviation. The data were statistically analyzed using SPSS software and groups were compared using Student's $t$ test with significant differences defined as $P<0.05$, whereas $P<0.01$ represented a highly significant difference.

\section{Declarations}

\section{Ethics approval and consent to participate}

Not applicable.

\section{Consent for publication}

Not applicable. 


\section{Availability of data and materials}

The datasets supporting the conclusions of this article are included within the article and its additional files.

Additional files

Additional file 1: Figure S1. Restriction maps of the recombinant plasmids containing lipA and (or) lipB in this study.

\section{Competing interests}

The authors declare that they have no competing interests.

\section{Authors' contributions}

ZY Shu designed and supervised the work. Feng Li participated in the construction of various recombinant plasmids, and purification of the recombinant lipase. WJ Jia produced the recombinant LipA. H Lin and XD Mu determined the triacylglycerol hydrolysis activity and the steryl ester hydrolysis activity of the recombinant LipA, respectively. YR Liu provided advice for the discussion. This manuscript was drafted by F Li and revised by ZY Shu. JZ Huang gave final approval of the version to be published. All authors have read and approved the final manuscript.

\section{Acknowledgements}

Not applicable.

\section{Authors' information}

Hong Lin is Ph.D. student of College of Life Sciences, Fujian Normal University.

Feng Li, Xiangduo Mu and Wenjing Jia are Master students of College of Life Sciences, Fujian Normal University.

Zhengyu Shu, Yanru Liu, and Jianzhong Huang are staffs of College of Life Sciences, Fujian Normal University.

\section{Funding}


This project has received funding from National Natural Science Foundation of China (No. 31370802 and No. 31870787) and Fujian Province Natural Science Foundation (No. 2017J01441).

\section{Author details}

${ }^{1}$ National \& Local United Engineering Research Center of Industrial Microbiology and Fermentation Technology, Ministry of Education, Fujian Normal University, Fuzhou 350117, China. ${ }^{2}$ Engineering Research Center of Industrial Microbiology, Ministry of Education, Fujian Normal University, Fuzhou 350117, China. ${ }^{3}$ Provincial University Key Laboratory of Cellular Stress Response and Metabolic Regulation, Fujian Normal University, Fuzhou 350117, China. ${ }^{4}$ College of Life Sciences, Fujian Normal University (Qishan campus), Fuzhou 350117, China.

\section{References}

1. Jaeger KE, Reetz MT. Microbial lipases form versatile tools for biotechnology. Trends Biotechnol. 1998;16:396-403.

2. Carvalho AC, Fonseca Tde S, de Mattos MC, de Oliveira Mda C, de Lemos TL, Molinari F, Romano D, Serra I. Recent advances in lipase-mediated preparation of pharmaceuticals and their intermediates. Int J Mol Sci. 2015;16:29682-716.

3. Hasan F, Shah AA, Hameed A. Industrial applications of microbial lipases. Enzyme Microb Tech. 2006;39:235-251.

4. Lang DA, Mannesse ML, de Haas GH, Verheij HM, Dijkstra BW. Structural basis of the chiral selectivity of Pseudomonas cepacia lipase. Eur J Biochem. 1998;254:333-40.

5. Pleiss J, Fischer M, Schmid RD. Anatomy of lipase binding sites: the scissile fatty acid binding site. Chem Phys Lipids. 1998;93:67-80.

6. Sánchez DA, Tonetto GM, Ferreira ML. Burkholderia cepacia lipase: a versatile catalyst in synthesis reactions. Biotechnol Bioeng. 2018;115:6-24.

7. Sasso F, Natalello A, Castoldi S, Lotti M, Santambrogio C, Grandori R. Burkholderia cepacia lipase is a promising biocatalyst for biofuel production. Biotechnol J. 2016;11:954-60.

8. Yang JK, Guo DY, Yan YJ. Cloning, expression and characterization of a novel thermal stable and short-chain alcohol tolerant lipase from Burkholderia cepacia strain G63. J Mol Catal B Enzym. 2007;45:91-6.

9. El Khattabi M, Van Gelder P, Bitter W, Tommassen J. Role of the calcium ion and the disulfide bond in the Burkholderia glumae lipase. J Mol Catal B Enzym. 2003;22:329-38.

10. Kim KK, Song HK, Shin DH, Hwang KY, Suh SW. The crystal structure of a triacylglycerol lipase from Pseudomonas cepacia reveals a highly open conformation in the absence of a bound inhibitor. Structure. 1997;5:173-85. 
11. Arpigny JL, Jaeger KE. Bacterial lipolytic enzymes: classification and properties. Biochem J. 1999;343:177-83.

12. Hausmann S, Jaeger KE. Lipolytic enzymes from bacteria. In: Timmis KN, editor. Handbook of hydrocarbon and lipid microbiology. Verlag Berlin Heidelberg: Springer; 2010. p.1099-126.

13. Jørgensen S, Skov KW, Diderichsen B. Cloning, sequence, and expression of a lipase gene from Pseudomonas cepacia lipase production in heterologous hosts requires two Pseudomonas genes. $\mathrm{J}$ Bacteriol. 1991;173:559-67.

14. Rosenau F, Tommassen J, Jaeger KE. Lipase-specific foldases. Chembiochem. 2004;5:152-61.

15. Chiarini L, Bevivino A, Dalmastri C, Tabacchioni S, Visca P. Burkholderia cepacia complex species health hazards and biotechnological potential. Trends Microbiol. 2006;14:277-86.

16. Mahenthiralingam E, Baldwin A, Dowson CG. Burkholderia cepacia complex bacteria opportunistic pathogens with important natural biology. J Appl Microbiol. 2008;104:1539-51.

17. Wang XQ, Yu XW, Xu Y. Homologous expression, purification and characterization of a novel highalkaline and thermal stable lipase from Burkholderia cepacia ATCC 25416. Enzyme Microb Tech. 2009;45:94-102.

18. Koga Y, Kobayashi K, Yang J, Nakano H, Yamane T. In vitro construction and screening of a Burkholderia cepacia lipase library using single-molecule PCR and cell-free protein synthesis. J Biosci Bioeng. 2002;94:84-6.

19. Quyen DT, Schmidt-Dannert C, Schmid RD. High-level formation of active Pseudomonas cepacia lipase after heterologous expression of the encoding gene and its modified chaperone in Escherichia coli and rapid in vitro refolding. Appl Environ Microbiol. 1999;65:787-94.

20. Madan B, Mishra P. Co-expression of the lipase and foldase of Pseudomonas aeruginosa to a functional lipase in Escherichia coli. Appl Microbiol Biotechnol. 2010;85:597-604.

21. Martini VP, Glogauer A, Müller-Santos M, lulek J, de Souza EM, Mitchell DA, Pedrosa FO, Krieger N. First co-expression of a lipase and its specific foldase obtained by metagenomics. Microb Cell Fact. 2014;13:171.

22. Quyen TD, Vu CH, Le GT. Enhancing functional production of a chaperone-dependent lipase in Escherichia coli using the dual expression cassette plasmid. Microb Cell Fact. 2012;11:29.

23. Wu X, You P, Su E, Xu J, Gao B, Wei D. In vivo functional expression of a screened P. aeruginosa chaperone-dependent lipase in E. coli. BMC Biotechnol. 2012;12:58.

24. Aamand JL, Hobson AH, Buckley CM, Jørgensen ST, Diderichsen B, McConnell DJ. Chaperonemediated activation in vivo of a Pseudomonas cepacia lipase. Mol Gen Genet. 1994;245:556-64.

25. Ihara F, Okamoto I, Akao K, Nihira T, Yamada Y. Lipase modulator protein (LimL) of Pseudomonas sp. strain 109. J Bacteriol. 1995;177:1254-8.

26. Reetz MT, Jaeger KE. Overexpression, immobilization and biotechnological application of Pseudomonas lipases. Chem Phys Lipids. 1998;93:3-14. 
27. Yang J, Kobayashi K, Iwasaki Y, Nakano H, Yamane T. In vitro analysis of roles of a disulfide bridge and a calcium binding site in activation of Pseudomonas sp. strain KWI-56 lipase. J Bacteriol. 2000;182:295-302.

28. Narayanan N, Khan M, Chou CP. Enhancing functional expression of heterologous Burkholderia lipase in Escherichia coli. Mol Biotechnol. 2011;47:130-43.

29. Ferrer M, Chernikova TN, Yakimov MM, Golyshin PN, Timmis KN. Chaperonins govern growth of Escherichia coli at low temperature. Nat Biotechnol. 2003;21:1266-7.

30. Sørensen HP, Mortensen KK. Soluble expression of recombinant proteins in the cytoplasm of Escherichia coli. Microb Cell Fact. 2005;4:1.

31. Liu YR, Qiu FJ, Shu ZY, Wang ZZ, Qiu LQ, Li X, Jiang XZ, Huang JZ. Purification and enzymatic characterization of the extracellular lipase from Burkholderia sp. ZYB002. J Fujian Normal Univ Nat Sci Ed. 2014;30:100-5.

32. Pauwels K, Van Gelder P. Affinity-based isolation of a bacterial lipase through steric chaperone interactions. Protein Expr Purif. 2008;59:342-8.

33. Ribeiro BD, de Castro AM, Coelho MA, Freire DM. Production and use of lipases in bioenergy: a review from the feedstocks to biodiesel production. Enzyme Res. 2011;1:615803.

34. Kontkanen $\mathrm{H}$, Tenkanen M, Fagerström R, Reinikainen T. Characterisation of steryl esterase activities in commercial lipase preparations. J Biotechnol. 2004;108:51-9.

35. Voget S, Knapp A, Poehlein A, Vollstedt C, Streit W, Daniel R, Jaeger KE. Complete genome sequence of the lipase producing strain Burkholderia glumae PG1. J Biotechnol. 2015;204:3-4.

36. Winsor GL, Khaira B, Van Rossum T, Lo R, Whiteside MD, Brinkman FS. The Burkholderia genome database: facilitating flexible queries and comparative analyses. Bioinformatics. 2008;24:2803-4.

37. El Khattabi M, Ockhuijsen C, Bitter W, Jaeger KE, Tommassen J. Specificity of the lipase-specific foldases of gram-negative bacteria and the role of the membrane anchor. Mol Gen Genet. 1999;261:770-6.

38. El Khattabi M, Van Gelder P, Bitter W, Tommassen J. Role of the lipase-specific foldase of Burkholderia glumae as a steric chaperone. J Biol Chem. 2000;275:26885-91.

39. Hayashi S, Abe M, Kimoto M, Furukawa S, Nakazawa T. The dsbA-dsbB disulfide bond formation system of Burkholderia cepacia is involved in the production of protease and alkaline phosphatase, motility, metal resistance, and multi-drug resistance. Microbiol Immunol. 2000;44:41-50.

40. Liebeton K, Zacharias A, Jaeger KE. Disulfide bond in Pseudomonas aeruginosa lipase stabilizes the structure but is not required for interaction with its foldase. J Bacteriol. 2001;183:597-603.

41. Kawata Y, Hongo K, Mizobata T, Nagai J. Chaperonin GroE-facilitated refolding of disulfide-bonded and reduced Taka-amylase A from Aspergillus oryzae. Protein Eng. 1998;11:1293-8.

42. Di Lorenzo M, Hidalgo A, Haas M, Bornscheuer UT. Heterologous production of functional forms of Rhizopus oryzae lipase in Escherichia coli. Appl Environ Microbiol. 2005;71:8974-7. 
43. Pauwels K, Lustig A, Wyns L, Tommassen J, Savvides SN, Van Gelder P. Structure of a membranebased steric chaperone in complex with its lipase substrate. Nat Struct Mol Biol. 2006;13:374-5.

44. Tanaka J, Ihara F, Nihira T, Yamada Y. A low-Mr lipase activation factor cooperating with lipase modulator protein LimL in Pseudomonas sp. strain 109. Microbiology. 1999;145:2875-80.

45. Tanaka J, Nihira T, Yamada Y. Glutathione as an essential factor for chaperon-mediated activation of lactonizing lipase (LipL) from Pseudomonas sp. 109. J Biochem. 2000;127:597-601.

46. Kim EK, Jang WH, Ko JH, Kang JS, Noh MJ, Yoo OJ. Lipase and its modulator from Pseudomonas sp. strain KFCC 10818: Proline-to-Glutamine substitution at position 112 induces formation of enzymatically active lipase in the absence of the modulator. J Bacteriol. 2001;183:5937-41.

47. Baldessari A, Iglesias LE. Lipase in green chemistry: acylation and alcoholysis on steroids and nucleosides. Methods Mol Biol. 2012;861:457-69.

48. Vaquero ME, Barriuso J, Martínez MJ, Prieto A. Properties, structure, and applications of microbial sterol esterases. Appl Microbiol Biotechnol. 2016;100:2047-61.

49. Takeda Y, Aono R, Doukyu N. Purification, characterization, and molecular cloning of organic-solventtolerant cholesterol esterase from cyclohexane-tolerant Burkholderia cepacia strain ST-200.

Extremophiles. 2006;10:269-77.

50. Shu Z, Lin H, Shi S, Mu X, Liu Y, Huang J. Cell-bound lipases from Burkholderia sp. ZYB002: gene sequence analysis, expression, enzymatic characterization, and 3D structural model. BMC Biotechnol. 2016;16:38.

51. Kapoor M, Gupta MN. Lipase promiscuity and its biochemical applications. Process Biochem. 2012;47:555-69.

52. Vallikivi I, Lille Ü, Lookene A, Metsala A, Sikk P, Tõugu V, Vija H, Villo L, Parve O. Lipase action on some non-triglyceride substrates. J Mol Catal B Enzym. 2003;22:279-98.

53. Laemmli UK. Cleavage of structural proteins during the assembly of the head of bacteriophage T4. Nature. 1970;227:680-5.

54. Bradford MM. A rapid and sensitive method for the quantitation of microgram quantities of protein utilizing the principle of protein-dye binding. Anal Biochem. 1976;72:248-54.

55. Kordel M, Hofmann B, Schomburg D, Schmid RD. Extracellular lipase of Pseudomonas sp. strain ATCC 21808: purification, characterization, crystallization, and preliminary X-Ray diffraction data. J Bacteriol. 1991;173:4836-41.

56. Stępień AE, Gonchar M. A simple method for the determination of the cholesterol esterase activity. Acta Biochim Pol. 2013;60:401-3.

57. Zhao H, Arnold FH. Directed evolution converts subtilisin E into a functional equivalent of thermitase. Protein Eng. 1999;12:47-53.

\section{Tables}


Table 1 Effect of different combination co-expression systems and induction temperatures on the soluble expression yield of lipA.

\begin{tabular}{|c|c|c|c|c|c|}
\hline \multirow[t]{2}{*}{ Host strain } & \multirow[t]{2}{*}{ Recombinant plasmids } & \multicolumn{4}{|c|}{ Induction temperature } \\
\hline & & $\begin{array}{c}30^{\circ} \mathrm{C} \\
\text { Lipase activity } \\
\left(\mathrm{U}^{\prime} / \mathrm{DD}_{600}\right)\end{array}$ & SA & $\begin{array}{c}20^{\circ} \mathrm{C} \\
\text { Lipase activity } \\
\left(\mathrm{U}^{-} \mathrm{OD}_{600}\right)\end{array}$ & SA \\
\hline \multirow[t]{8}{*}{$\begin{array}{l}\text { E. coliBL21 } \\
\text { (DE3) }\end{array}$} & $\begin{array}{l}\text { pEDSF-lipB-lipA } \\
\text { pACYCDuet-B1A2 }\end{array}$ & $\begin{array}{l}1.8 \pm 0.1 \\
6.5 \pm 0.2\end{array}$ & * & $\begin{array}{c}2.8 \pm 0.1 \\
53.0 \pm 1.1\end{array}$ & * \\
\hline & $\begin{array}{l}\text { pACYCDuet-B1A2 and } \\
\text { pETDuet-B1 }\end{array}$ & $6.3 \pm 0.1$ & * & $30.4 \pm 0.3$ & \\
\hline & $\begin{array}{l}\text { pETDuet-A1B2 } \\
\text { pETDuet-B1A2 } \\
\text { pETDuet-B1A2 and }\end{array}$ & $\begin{array}{l}1.7 \pm 0.1 \\
3.9 \pm 0.1 \\
3.7 \pm 0.3\end{array}$ & * & $\begin{array}{l}2.9 \pm 0.04 \\
49.7 \pm 0.6 \\
38.7 \pm 1.0\end{array}$ & * \\
\hline & $\begin{array}{l}\text { pACYCDuet-B1 } \\
\text { pET28a-lipB and pACYCDuet- } \\
\text { A1 }\end{array}$ & $2.6 \pm 0.1$ & & $17.1 \pm 0.2$ & \\
\hline & pET28a-lipA and pACYCDuet- & ND & & ND & \\
\hline & $\begin{array}{l}\text { pACYCDuet-B1A2 and } \\
\text { DETDuet-A1B2 }\end{array}$ & $12.6 \pm 1.0$ & \# & $38.2 \pm 1.4$ & \# \\
\hline & $\begin{array}{l}\text { PACYCDuet-B1A2 and } \\
\text { DFTDuet-B1A2 }\end{array}$ & $9.9 \pm 0.4$ & \# & $36.6 \pm 1.1$ & \# \\
\hline & $\begin{array}{l}\text { pEDSF-lipB-lipA and } \\
\text { pETDuet-B1A2 }\end{array}$ & $12.4 \pm 0.5$ & \# & $36.2 \pm 0.9$ & \# \\
\hline \multirow[t]{7}{*}{$\begin{array}{l}\text { E. coliOrigami } 2 \\
\text { (DE3) }\end{array}$} & $\begin{array}{l}\text { pEDSF-lipB-lipA } \\
\text { pACYCDuet-B1A2 } \\
\text { pACYCDuet-B1A2 and } \\
\text { pETDuet-B1 }\end{array}$ & $\begin{array}{l}2.4 \pm 0.6 \\
42.9 \pm 1.0 \\
30.3 \pm 0.9\end{array}$ & * & $\begin{array}{l}4.0 \pm 0.04 \\
73.7 \pm 1.3 \\
40.5 \pm 0.6\end{array}$ & * \\
\hline & $\begin{array}{l}\text { pETDuet-A1B2 } \\
\text { pETDuet-B1A2 } \\
\text { pETDuet-B1A2 and }\end{array}$ & $\begin{array}{c}2.3 \pm 0.3 \\
30.9 \pm 0.3 \\
22.5 \pm 0.4\end{array}$ & * & $\begin{array}{c}3.5 \pm 0.03 \\
100.4 \pm 0.7 \\
70.8 \pm 1.0\end{array}$ & * \\
\hline & $\begin{array}{l}\text { pET28a-lipB and pACYCDuet- } \\
\text { A1 }\end{array}$ & $8.0 \pm 0.1$ & & $34.7 \pm 0.3$ & \\
\hline & $\begin{array}{l}\text { pET28a-lipA and pACYCDuet- } \\
\text { B1 }\end{array}$ & ND & & $0.3 \pm 0.02$ & \\
\hline & $\begin{array}{l}\text { pACYCDuet-B1A2 and } \\
\text { pETDuet-A1B2 }\end{array}$ & $31.6 \pm 1.6$ & \# & $78.9 \pm 1.1$ & \# \\
\hline & $\begin{array}{l}\text { pACYCDuet-B1A2 and } \\
\text { pETDuet-B1A2 }\end{array}$ & $34.7 \pm 1.7$ & \# & $77.9 \pm 1.1$ & \# \\
\hline & $\begin{array}{l}\text { pEDSF-lipB-lipA and } \\
\text { pETDuet-B1A2 }\end{array}$ & $34.4 \pm 1.4$ & \# & $76.1 \pm 1.5$ & \# \\
\hline
\end{tabular}

SA: statistical analysis. \#:P<0.05; *:P<0.01.

Table 2 Substrate specificity of the recombinant LipA towards 4-nitrophenyl esters and steryl esters 


\begin{tabular}{lclc}
\hline Substrate for lipase activity & Specific activity & Substrate for steryl esterase activity & Specific activity \\
& $(\mathrm{U} / \mathrm{mg})$ & & $(\mathrm{mU} / \mathrm{mg})$ \\
\hline 4-nitrophenyl palmitate $\left(\mathrm{C}_{16}\right)$ & $253.8 \pm 6.3$ & Cholesterol linoleate & $1111.5 \pm 6.2$ \\
4-nitrophenyl myristate $\left(\mathrm{C}_{14}\right)$ & $229.0 \pm 4.8$ & Cholesterol oleate & $80.8 \pm 2.7$ \\
4-nitrophenyl laurate $\left(\mathrm{C}_{12}\right)$ & $547.0 \pm 6.7$ & Cholesterol stearate & $47.0 \pm 3.5$ \\
4-nitrophenyl decanoate $\left(\mathrm{C}_{10}\right)$ & $638.9 \pm 10.3$ & Cholesterol palmitate & $288.9 \pm 1.8$ \\
4-nitrophenyl octanoate $\left(\mathrm{C}_{8}\right)$ & $371.4 \pm 7.2$ & & \\
4-nitrophenyl butyrate $\left(\mathrm{C}_{4}\right)$ & $129.4 \pm 9.6$ & & \\
\hline
\end{tabular}

\begin{tabular}{lll}
\hline \multicolumn{1}{c}{ Strains and plasmids } & \multicolumn{1}{c}{ Description } & Source \\
\hline Strains & Host strain for plasmid amplification & \\
E. coliDH5a & Expression host strain & TAKARA \\
E. coliBL21(DE3) & Novagen \\
E. coli Origami 2 (DE3) & Expression host strain & Novagen \\
Plasmids & & \\
pMD18T-lipAB & pMD18T containing the PCR-amplified lipA and lipB & Reference 50 \\
pEDSF-lipB-lipA & pACYCDuet with insertion of lipA at MCS1 and lipB at MCS2 & Reference 50 \\
pACYCDuet-B1A2 & pACYCDuet with insertion of lipB at MCS1 and lipA at MCS2 & This study \\
pETDuet-A1B2 & pETDuet with insertion of lipA at MCS1 and lipB at MCS2 & This study \\
pETDuet-B1A2 & pETDuet with insertion of lipB at MCS1 and lipA at MCS2 & This study \\
pACYCDuet-A1 & pACYCDuet with insertion of lipA at MCS1 & This study \\
pACYCDuet-B1 & pACYCDuet with insertion of lipB at MCS1 & This study \\
pETDuet-B1 & pETDuet with insertion of lipB at MCS1 & This study \\
pETDuet-B2 & pETDuet with insertion of lipB at MCS2 & This study \\
pET28a-lipA & Expression plasmid containing lipA gene & This study \\
pET28a-lipB & Expression plasmid containing lipB gene & This study \\
\hline
\end{tabular}

Table 3 Strains and plasmids used in the current study

Table 4 Oligonucleotide primers used in the current study ${ }^{a}$ 


\begin{tabular}{|c|c|c|c|}
\hline Primers & $\begin{array}{c}\text { Oligonucleotide sequence } \\
\qquad\left(5^{\prime} \text { to } 3^{\prime}\right)\end{array}$ & $\begin{array}{c}\text { Annealing } \\
\text { temperature }\left({ }^{\circ} \mathrm{C}\right)\end{array}$ & PCR products \\
\hline lipBEF1 & CGCGGATCCGCCGCCGTCGCTCGC & 60 & The coding region for the truncated LipB \\
\hline lipBER1 & CCCAAGCTTTTACTGCATGCTGCCG & & $\begin{array}{l}\text { (for pACYCDuet-B1A2 and pETDuet-B1A2 } \\
\text { construction) }\end{array}$ \\
\hline lipAEF1 & GAAGATCTCGCCGATGGCTACG & 55 & The coding region for the mature LipA \\
\hline lipAER1 & GAGATATCTTACACGCCCGCCA & & $\begin{array}{l}\text { (for pACYCDuet-B1A2 and pETDuet-B1A2 } \\
\text { construction) }\end{array}$ \\
\hline 1ірAEF2 & TATGGATCCGCCGATGGCTACGCGGCGACGC & 58 & The coding region for the mature LipA \\
\hline 1ipAER2 & CTTAAGCTTTTACACGCCCGCCAGCTTCAG & & (for pET28a-lipA construction) \\
\hline lipBEF2 & CGCGGATCCCCGCCGTCGCTCGCC & 59 & The coding region for the truncated LipB \\
\hline lipBER1 & CCCAAGCTTTTACTGCATGCTGCCG & & (for pET28a-lipB construction) \\
\hline
\end{tabular}

$\mathbf{a}_{\text {underlined nucleotides: restriction endonuclease site. }}$

\section{Figures}

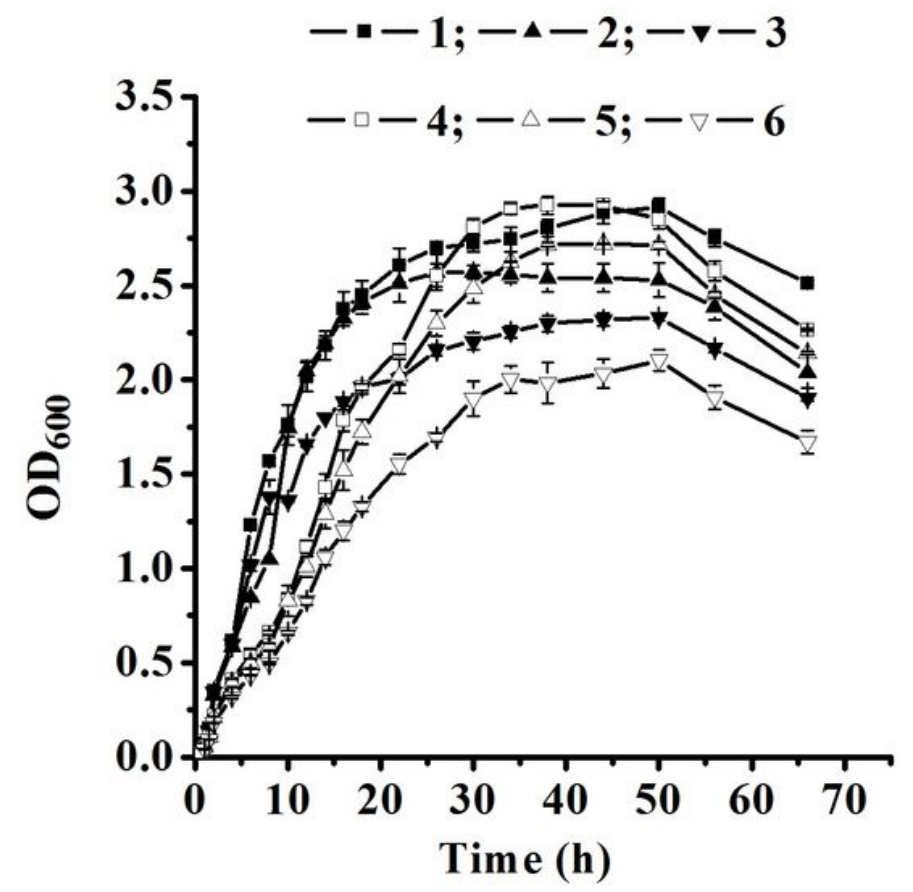

A

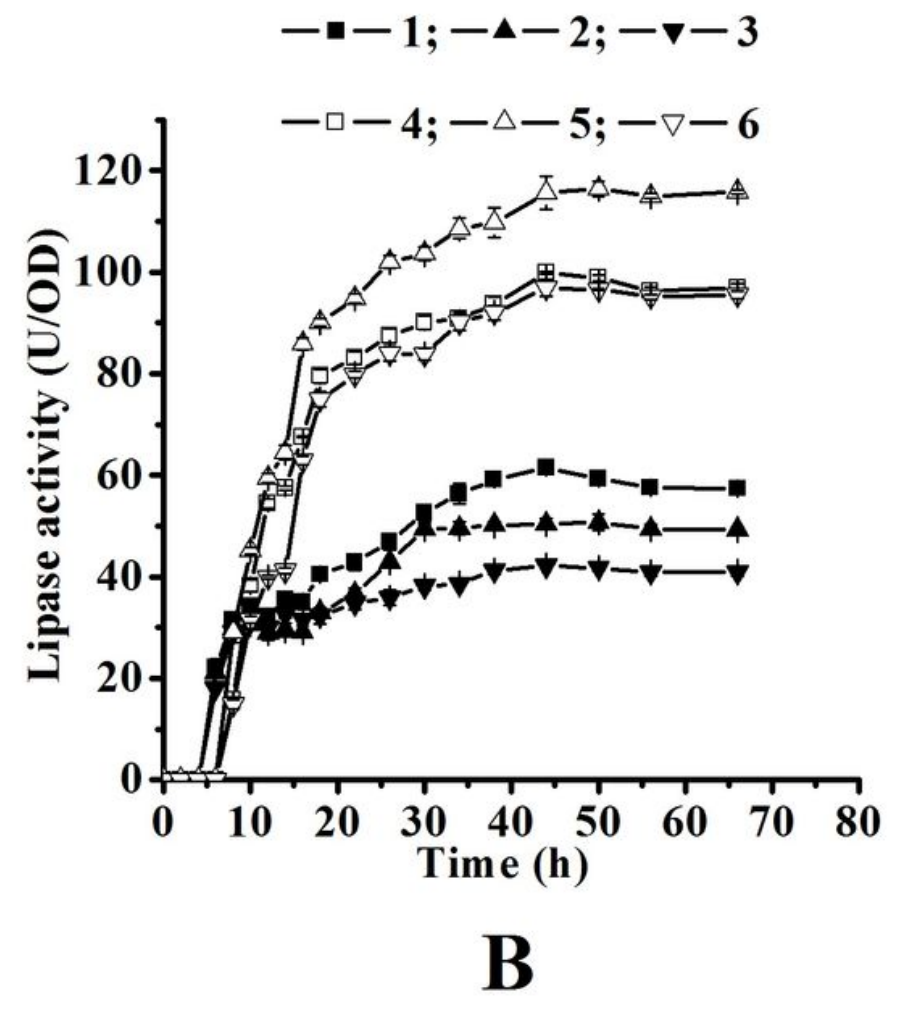

Figure 1 
Growth curves (A) and kinetic curves for soluble LipA (B) of various recombinant E. coli strains carrying co-expression combination system of lipA and lipB cultivated at $20^{\circ} \mathrm{C}$. 1: E. coli BL21 (DE3)/pACYCDuetB1A2; 2: E. coli BL21 (DE3)/pETDuet-B1A2; 3: E. coli BL21 (DE3)/pACYCDuet-B1A2 plus pETDuet-B1A2; 4: E. coli Origami 2 (DE3)/pACYCDuet-B1A2; 5: E. coli Origami 2 (DE3)/pETDuet-B1A2; 6: E. coli Origami 2 (DE3)/pACYCDuet-B1A2 plus pETDuet-B1A2.

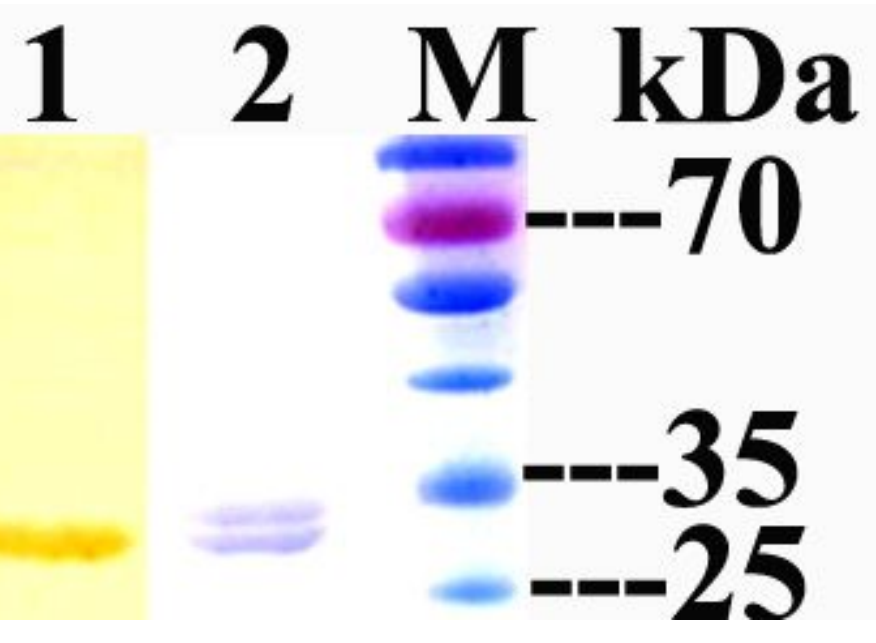

Figure 2

SDS-PAGE analysis and western blotting analysis of the purified LipA/LipB complex from cell-free supernatant of E. coli Origami 2 (DE3)/pETDuet-B1A2 lysate using HisTrapTM HP affinity chromatography. Lane 1: western blotting analysis of anti-His tag antibody of the purified LipA/LipB complex; lane 2: SDS-PAGE analysis of the purified LipA/LipB complex; M: protein molecular weight marker. 


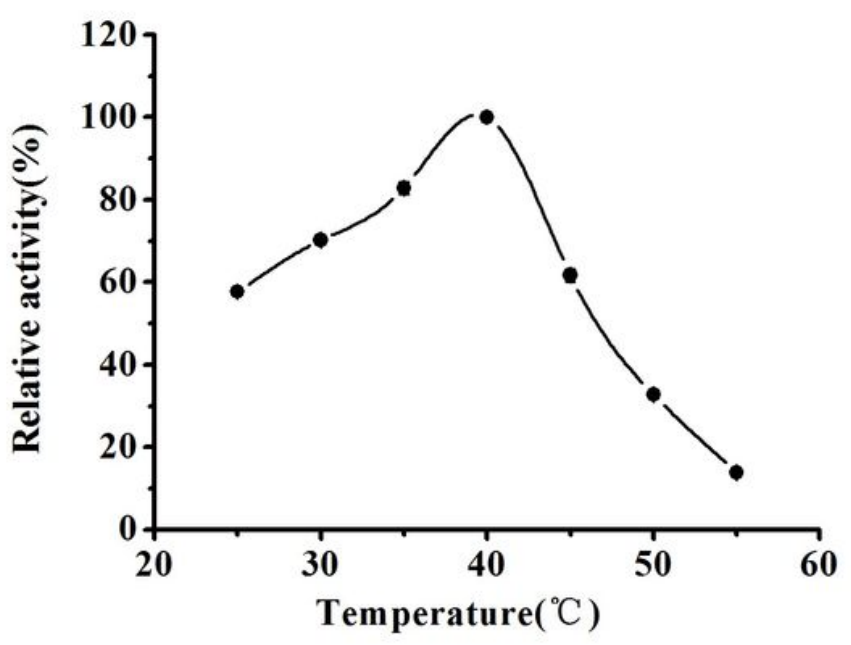

A

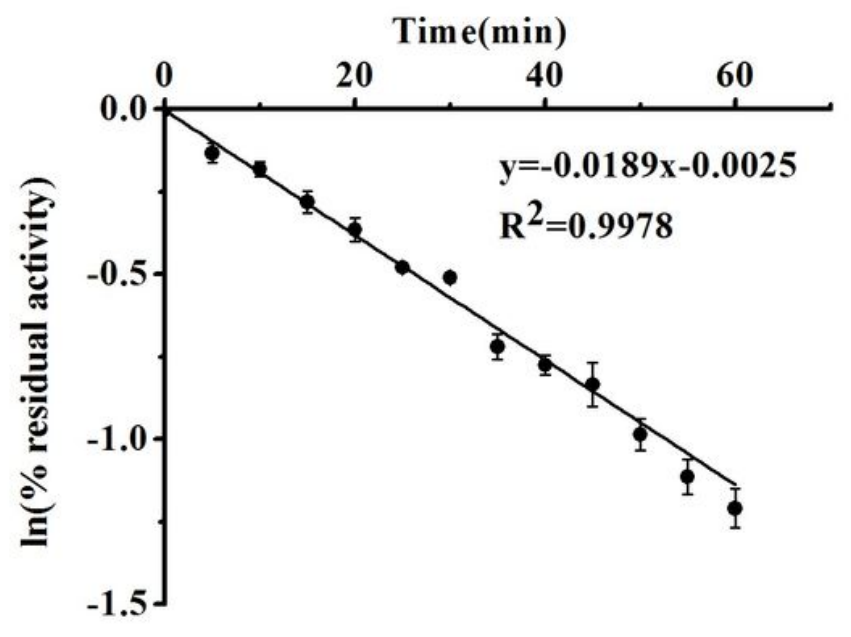

C

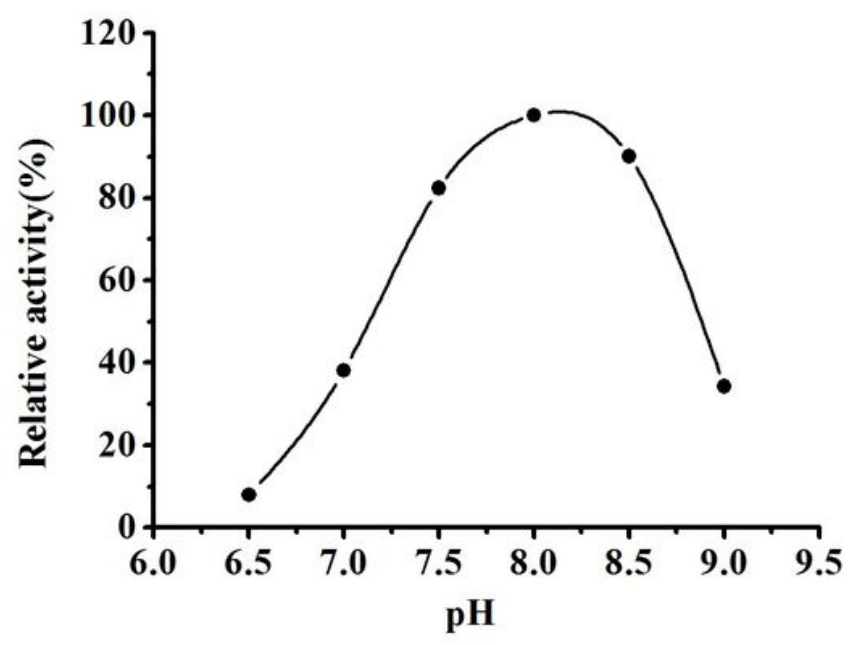

B

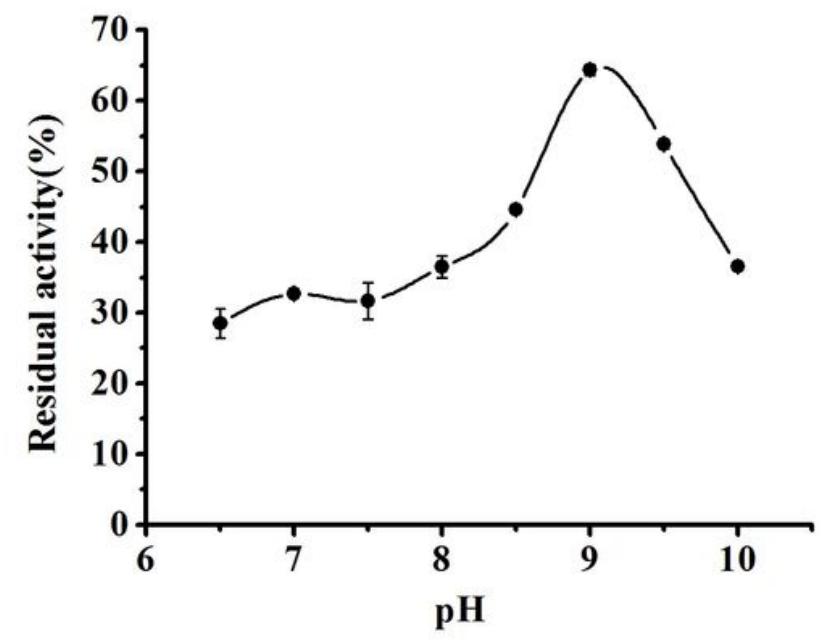

D

Figure 3

Enzymatic characterization of the purified LipA. (A): Effect of temperature on LipA activity; (B): Effect of pH on LipA activity; (C): Effect of temperature on LipA stability; (D): Effect of pH on LipA stability. 


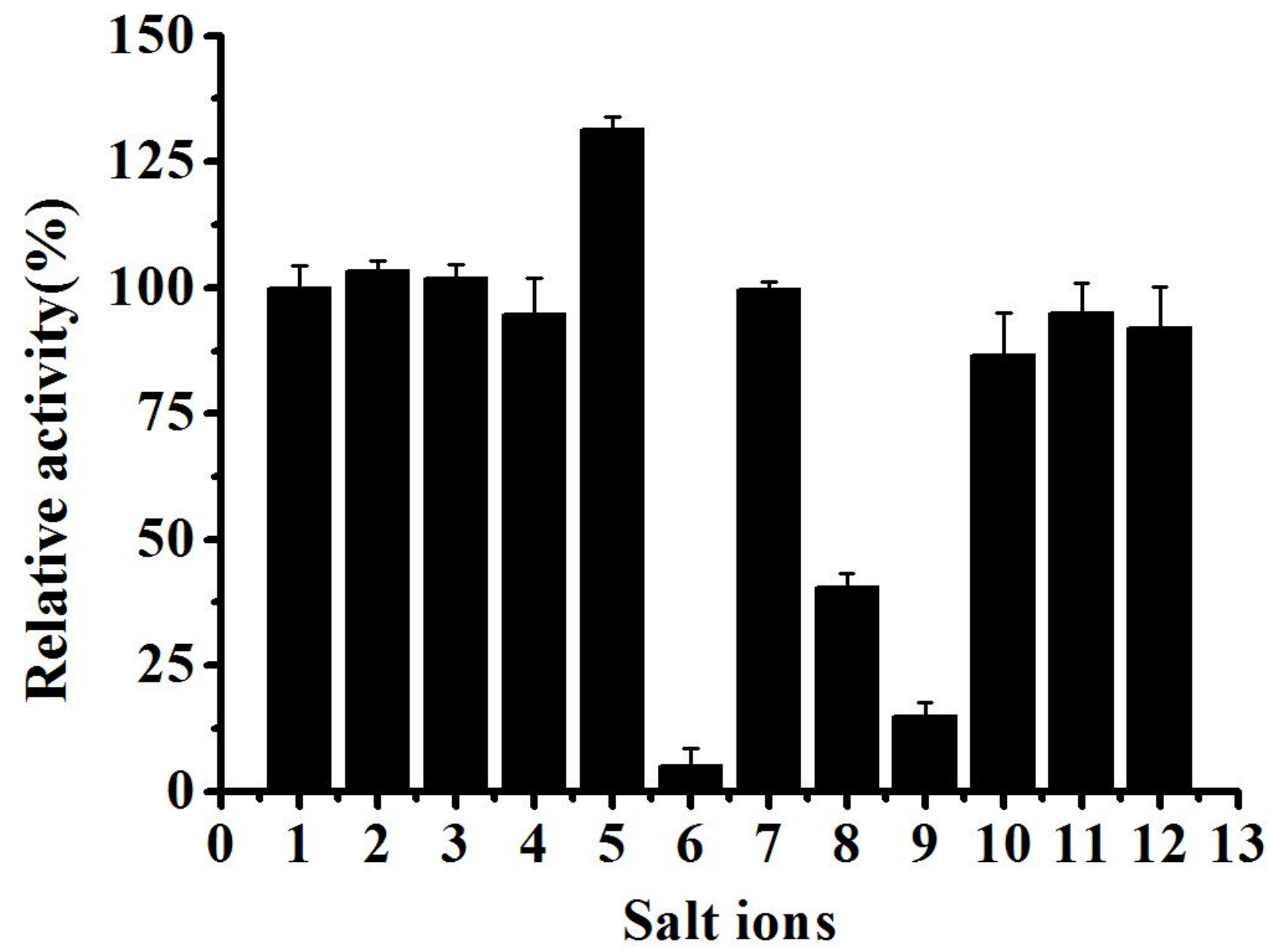

Figure 4

Effect of different bivalent salt ions and EDTA on the recombinant LipA activity. 1: Control; 2: $\mathrm{NaCl} ; 3: \mathrm{KCl}$; 4: $\mathrm{BaCl}$; 5: $\mathrm{MgCl} 2$; 6: $\mathrm{FeCl} 3$; 7: $\mathrm{CaCl} 2$; 8: $\mathrm{ZnCl} 2$; 9: $\mathrm{CuCl} 2$; 10: AlCl3; 11: $\mathrm{MnCl} 2$; 12: EDTA. 


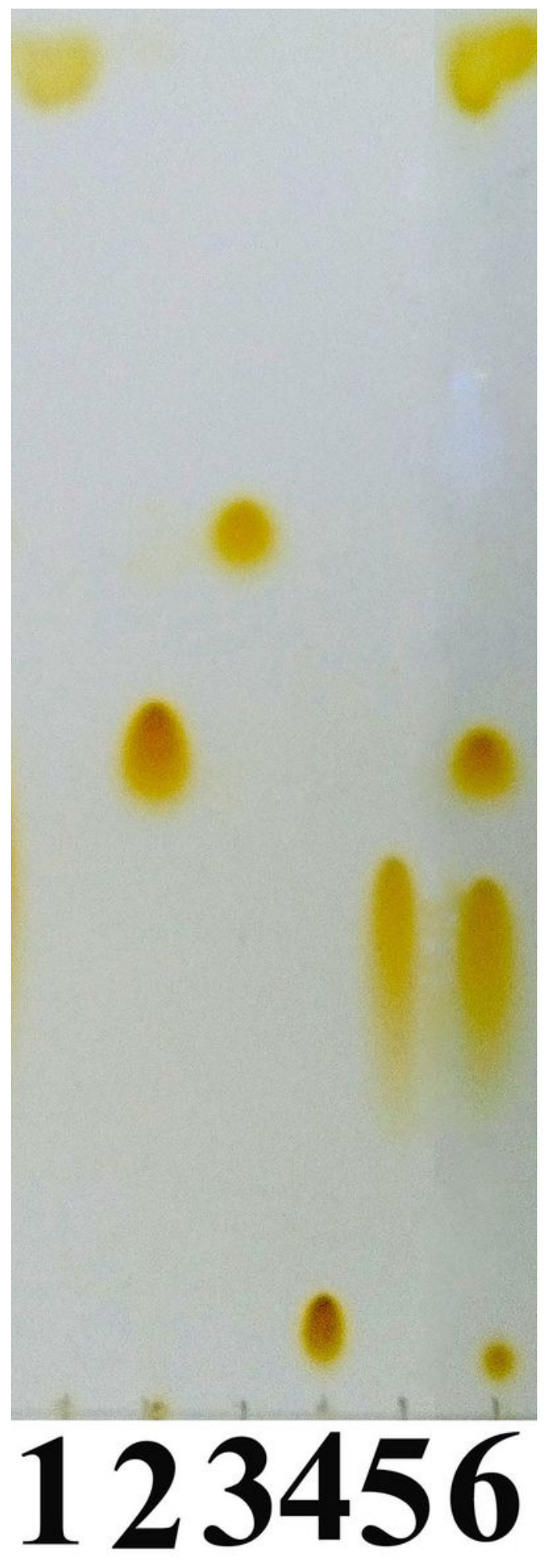

Figure 5

Thin-layer chromatogram of the hydrolysis products of triolein catalyzed by LipA. Lane 1: Triolein; Lane 2: 1,2-diolein; Lane 3: 1,3-diolein; Lane 4: 1-monoolein; Lane 5: oleic acid; Lane 6: hydrolysis products of triolein.

\section{Supplementary Files}


This is a list of supplementary files associated with this preprint. Click to download.

- supplement1.doc 